\title{
High Througput Multicore Server Dengan Kernel Bypass
}

\author{
Dimas Febriyan Priambodo \\ Jurusan Ilmu Komputer dan Elektronika, FMIPA UGM, Yogyakarta \\ e-mail: dimas.febriyan@ poltekssn.ac.id
}

\begin{abstract}
Kernel performs one part of the overall operating system utility as a bridge between the user and the hardware. In multi core hardware, the kernel was also created with a general approach so it needs to be adjusted for specific purposes. Kernels for servers using common Kernels have many limitations, such as single socket descriptor, single IRQ, and lack of pooling so that they require some modification to run optimally. Kernel bypass is a method by eliminating the automation of a server used to realize a server, namely high throughput. Kernel bypass is a combination of techniques, modification at the driver level with hashing $r x$ signal and modification of multiple receivers with multiple ip receivers, multiple thread receivers, and multiple port listeners. This combined modification makes the server more reliable with an average throughput increase of $250.44 \%$.
\end{abstract}

Keyword: kernel bypass, hashing rx, multiple ip receiver, multiple thread receiver, multiple port listener

\section{PENDAHULUAN}

Sebuah sistem operasi dibangun dengan dua komponen utama yaitu dengan GUI (Graphical User Interface) dan kernel sebagai penghubung antara user dan mesin. Kernel didesain untuk melakukan keseluruhan dari proses yang berlangsung pada komputer. Pendekatan keumuman dijadikan aspek utama perancangan dari sebuah kernel karena untuk melayani kebutuhan user secara umum.

Peladen merupakan seperangkat komputer super atau biasanya berupa High Performance Computer (HPC). Pada komputer peladen biasanya akan ditanamkan sistem operasi khusus peladen yang mempunyai utilitas khusus. Namun tidak jarang server menggunakan sistem operasi yang sama dengan sistem operasi personal computer. Linux yang banyak digunakan pada peladen mempunyai kernel yang sama dengan yang digunakan oleh personal computer. Sehingga penelitian ini dilakukan untuk dapat mengoptimalisasi sistem operasi linux pada khususnya untuk mendapatkan peladen yang optimal khususnya dari sisi throughput.

Program client server dibuat sebagai salah satu uji pendahuluan yang menunjukkan kelemahan default kernel dalam menjalankan fungsinya sebagai peladen terlebih dalam sistem multicore. Gambar 1 menunjukkan tidak ada perbedaan signifikan terhadap waktu pemrosesan baik dalam core atau inti yang sama maupun dalam inti yang berbeda dan bisa disimpulkan HyperThreading bekerja dengan baik karena menjalankan program dalam satu inti yang sama dan tidak mempengaruhi kinerja CPU lainnya. Hasil tersebut juga memberi kesimpulan bahwa kinerja singgle CPU tidak terlalu bagus karena bisa berarti tidak effisien. 


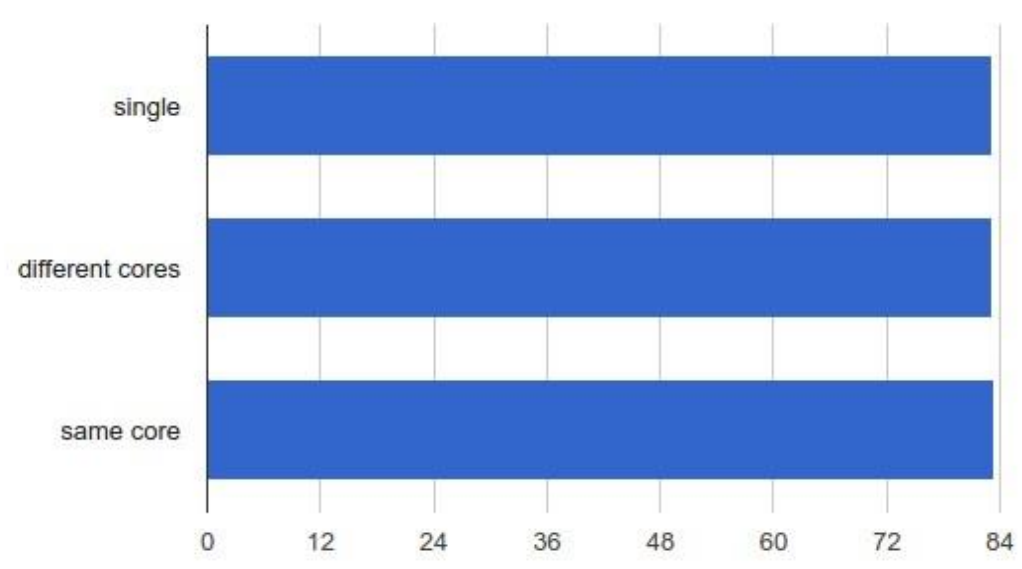

Gambar 1. Hasil Core Performance test 1

Gambar 2 menunjukkan perbedaan yang cukup signifikan pada pemrosesan program yang kompleks dimana menunjukkan waktu proses yang sama pada core yang berbeda namun akan cenderung menurunkan performance sebesar $75 \%$ (tujuh puluh lima persen) pada core yang sama $(H T)$. Analisis juga menunjukkan, dengan menggunakan 2 (dua) thread akan melakukan pemrosesan yang lebih cepat. Menggunakan 2 thread menghasilkan catatan waktu $945 \mathrm{~ms}$ dan untuk single thread memerlukan waktu (540 ms x 2) $1080 \mathrm{~ms}$.

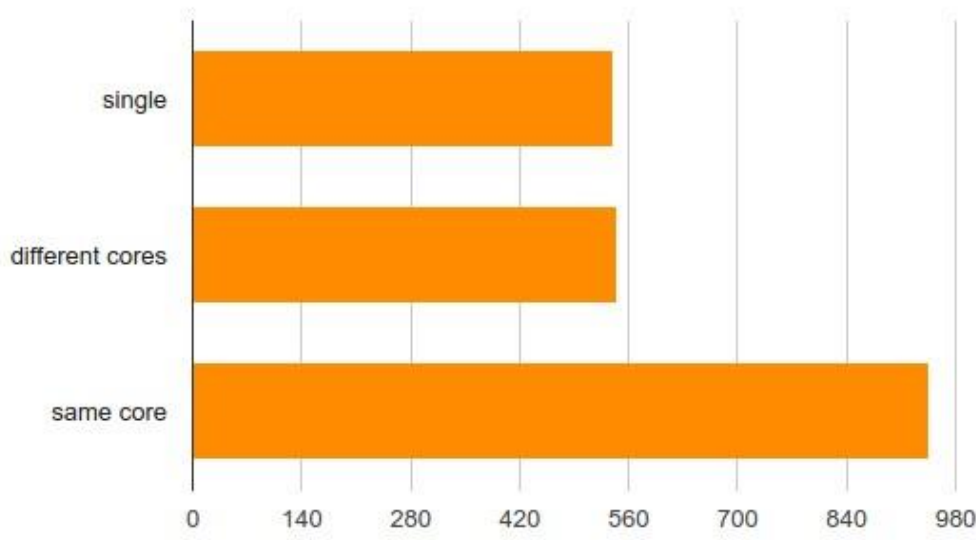

Gambar 2. Hasil Core Performance test 2

Gambar 2 juga memberikan kesimpulan perlu adanya sistem untuk menghindari migrasi interupsi yang sering terjadi pada default kernel multicore processor. Pada default kernel menggunakan metode round robin dalam pengelolaan interupsinya, sehingga ada suatu waktu dimana beban proses dibabankan pada sharing core sehingga menggunakan share memory dan mengakibatkan beban salah satu core processor menjadi berlebih, di sisi core yang lain mengalami free resource.

Server peladen yang berkembang ke arah multicore membutuhkan modifikasi berdasar konsep multicore aware. Membuat sistem yang multicore aware tidak hanya berhubungan dengan affinity aplikasi untuk membaginya pada CPU saja, namun juga berkaitan dengan hardware lainnya khususnya yang memberikan interupt kepada CPU pada peladen. Modifikasi untuk pengaturan signal dengan memodifikasi algoritma hashing menjadi multi queue untuk mengatasi kekurangan single IRQ pada kernel. Multi queue juga berarti mengaktifkan multi thread interupsi dan memaksanya secara manual menuju core yang berlainan. 
Pemaparan permasalahan diatas juga membuka urgensi untuk melakukan modifikasi pada port listener sehingga tidak terjadi lock pada default kernel, dengan binding socket maka setiap port dapat digunakan secara bersamaan oleh semua CPU tanpa terjadi lock dan proses waiting yang meningkatkan load dari processor. Penggabungan modifikasi ini diharapkan menjadi jawaban kebutuhan komputer peladen yang baik ditunjukkan dengan throughput yang tinggi.

\section{TINJAUAN PUSTAKA}

Penelitian ini mengacu pada beberapa referensi sumber pustaka yang berasal dari penelitian yang sudah dilakukan sebelumnya. Adapun beberapa penelitiannya yaitu simulasi pengaruh core affinity pada kenaikan throughput (Hanford et al., 2015). Penelitian ini melengkapi kedua penelitian diatas yang berkesimpulan peningkatan performance proses menggunakan thread pada core yang berbeda namun harus pada socket yang sama menjadi nyata dengan metode kernel bypass .

Penerapan teknologi socket mengacu pada NUMA (Non Uniform Memory Access) dikerjakan pada simulasi yang dilakukan oleh (Angelo et al., 2016) yang berkonsentrasi pada thread sceduling. Sejalan hasil simulasi tersebut Penelitian (Bo et al., 2016), (Diener et al.,2016) juga menyatakan peningkatan performance dengan NUMA. NUMA mampu meningkatkan performance dengan menghalangi perpindahan thread melalui partitioning memory. Bertentangan dengan beberapa penelitian tersebut, penelitian ini menjawab apakah NUMA memang solusi yang tepat untuk meningkatkan kemampuan peladen atau ada kombinasi yang lebih baik. Jika diperhatikan lebih detil beberapa penelitian tentang NUMA diatas belum menggunakan program yang cache sensitive sehingga tersamarkan peningkatannya. Peningkatan optimal terjadi jika proses diperoleh dan diolah dalam 1 (satu) interface socket yang sama. Proses pengolahan message dengan cache sensitive memungkinkan terjadi perpindahan socket karena program akan melakukan pencarian latency terbaik.

Pertukaran data atau large scale data replication, data harus dilewatkan melalui Wide Area Network (WAN) yang merupakan inter sistem dan mempunyai banyak batasan. Penelitian ini memberikan rekomendasi pentingnya sebuah hardware mampu mengatur affinity baik core maupun socket dalam melakukan pemrosesan penerimaan data sehingga mengoptimalkan sistem secara keseluruhan. Penelitian ini semakin mengukuhkan pentingnya mengatur sebuah affinity khususnya dalam sebuah network karena didalam sebuah hardware meskipun dalam satu kesatuan motherboard juga merupakan jaringan network atau disebut inter system.

Perkembangan hardware sayangnya tidak seiring dengan perkembangan penggunaan software. Kesalahan programmer dalam membuat program dikarenakan memang beberapa developer tidak memasukkan fitur untuk menangani perkembangan multicore, hal ini membuat programmer terbiasa untuk menghasilkan program yang tidak core aware. Program yang tidak core aware akan cenderung tidak efisien. Dalam gambaran sederhana, ada beberapa program yang tidak memunculkan perbedaan signifikan jika dikerjakan di core i3 dan core i5 padahal biaya yang dikeluarkan untuk membeli hardware tersebut tidaklah murah. Beberapa kasus pada program juga terlihat dari aplikasi yang masih menggunakan database access. Access tidak dirancang untuk dikerjakan dalam beberapa akses secara simultan sehingga tidak akan memproses request sebelum pendahulunya selesai. Hal ini hanya akan antrian sehingga dapat disimpulkan dengan menggunakan basis data Access di multicore tidak memberi keuntungan lebih. Namun menggunakan multicore akan membantu karena memberi overhead tambahan untuk mengelola concurrency pada akses database. Pada penelitian oleh (Gu et al., 2014) Operating System sendiri hingga saat penelitian berlangsung memberikan kendala dalam menganalisa termasuk juga dalam $C P U$ 
affinity flow, socket access, lock contention sehingga menggunakan aplikasi pihak ketiga yang menanganinya. Berkaitan dengan minimnya penelitian dan aplikasi yang khusus untuk affinity maka penelitian ini bertujuan untuk memberikan gambaran sehingga memberi perhatian lebih kepada peneliti lainnya.

Perkembangan kernel Operating System (OS) yang menangani network untuk multicore baru mulai berkembang sejak analisis signal processing (Fusco \& Deri, 2010) yang memberikan rekomendasi tentang pentingnya pengelolaan signal khususnya $r x$ atau receive signal dan membaginya kedalam beberapa quеие. Meskipun belum memberikan hasil namun penelitian tersebut membuka open issue berkenaan pengelolaan signal secara parallel. Berdasar penelitian diatas diciptakanlah teknologi RSS (Receive Side Scalling) yang mencoba memberikan solusi pada Operating System. RSS membagi load ke beberapa quеие dan meneruskannya ke beberapa core. Pemrosesan secara parallel akan menaikan kemampuan proses namun tidak berbanding lurus pada latency terutama jika rx queue dikerjakan oleh CPU yang sedang sibuk. Penelitian ini memberikan peluang penelitian berikutnya dikarenakan keterbatasan RSS sebab pada dasarnya komputer tidak mengetahui processor mana yang baik untuk melakukan proses.

Penelitian ini juga memberikan dukungan terhadap penelitian yang dilakukan oleh (Huang et al., 2010) dengan menggunakan pooling didukung hashing table untuk memodifikasi signal rx. Dalam usulan ini juga mencoba untuk menjawab analisis dari (Rivera et al., 2014) yang mengungkapkan penurunan performance terhadap UDP socket dalam penanganan multicore karena masing - masing core melakukan lock pada port yang sama. Multi receiver diterapkan dalam penelitian ini bertujuan untuk menaikkan througput meskipun menggunakan port yang sama, yaitu dengan menggunakan skema bind port sebelum melakukan accept().

Sistem ini disuguhkan melalui multi NIC yang diharapkan mampu meningkatkan throughput sehingga mempunyai scalability yang lebih, sejalan dengan penelitian oleh (Galagan et al., 2013). Selain itu memodifikasi signal transmit dan receive yang selama ini merupakan 1 (satu) kesatuan diubah menjadi beberapa bagian dalam sebuah hash sehingga diharapkan signal dapat dikerjakan secara multicore.

Selain itu usulan ini juga akan memberikan solusi lain dari penelitian dari (Jie et al., 2016) yang mengaktifkan receive offload untuk melakukan modifikasi dengan meng-generate ulang ACK pada Large Packet untuk meningkatkan throughput. Penelitian ini mencoba memberikan beberapa modifikasi yang lebih mengacu pada protocol UDP tanpa receive offload namun dengan tujuan yang sama yaitu peningkatan throughput. Hal ini dilakukan karena penelitian ini kedepannya diharapkan untuk dapat diimplementasikan pada real time aplication yang dimana kebanyakan menggunakan protocol UDP.

\section{METODE PENELITIAN}

Penelitian dimulai dengan meneliti perbedaan antara shared core dan dedicated core melalui membuat program looping workload sehingga diperoleh grafik perbedaan waktu dalam mili second ( $m s$ ). Langkah berikutnya menentukan besaran throughput sistem server default dengan menggunakan program sender dan receiver. Angka standar default digunakan sebagai parameter keberhasilan modifikasi pada setiap langkah modifikasi yang disebut juga dengan metode kernel bypass . Modifikasi ini terdiri dari hashing signal receive yang ditujukan untuk membagi signal menjadi beberapa queue yang secara default merupakan satu queue pada ethernet card. Modifikasi dilakukan menggunakan multiple IP (Internet Protocol) receiver yang ditujukan untuk membagi load dan membagi interupt menjadi beberapa bagian sehingga throughput meningkat serta melakukan affinity pada thread dan lebih lanjut disebut sebagai multi thread receiver. Modifikasi yang dilakukan 
tersebut juga mengatasi limitasi dari batasan dalam menerima interupt, yang bisa dipastikan hampir mustahil untuk menerima paket data lebih besar dari pemrosesan singgle CPU. Satu interupt biasanya hanya untuk satu ethernet atau peripheral. Modifikasi berikutnya dilakukan dengan menggunakan bind port yang ditujukan untuk membuat multi socket listener menyesuaikan analisis (Rivera et al., 2014). Secara garis besar modifikasi diatas ditunjukkan pada gambar 3 .

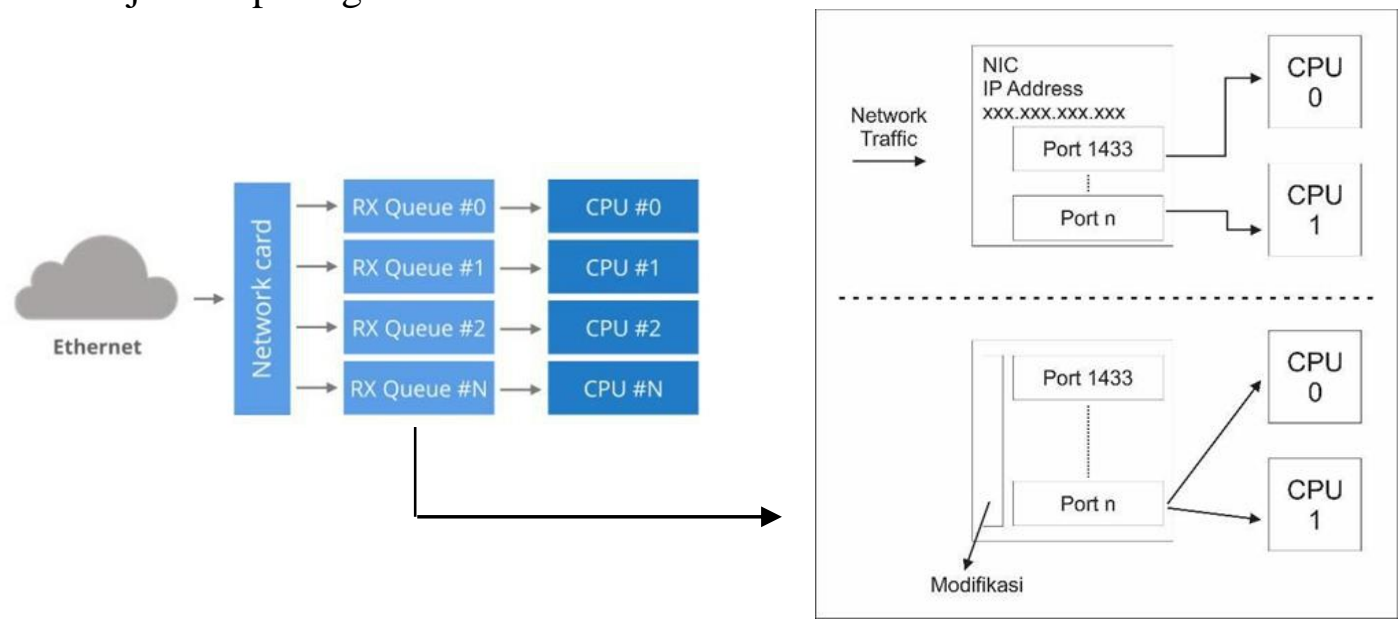

Gambar 3. Gambaran Modifikasi kernel bypass

\subsection{Core Performance}

Pembuatan program untuk looping thread menjadi bagian pertama dari pengujian pertama yang digunakan untuk mengetahui apakah benar OS (Operating System) bisa memindah thread berdasar looping yang dibuat. Pada bagian ini akan memunculkan capture gambar yang bisa terlihat seberapa sering thread akan berpindah.

Bagian kedua akan dibuat coding untuk melakukan pinning secara pasti ke CPU(Central Proccessing Unit) sehingga mengunci thread agar tidak berpindah. Proses affinity dengan menempatkan interupt ada spesifik CPU akan meningkatkan performance proses sesuai dengan pembahasan dari (Shambharkar, 2015).

Pada bagian inti atau performance demo antara core sharing dan separate core diuji dan disajikan dalam time series. Program akan menciptakan workload dan dibebankan pada logical CPU dalam pararel thread serta membandingkannya dengan single core. Pararel thread diperjelas dengan membaginya menjadi 2 bagian yaitu yang menggunakan thread pada core yang sama dan yang mengunakan thread pada core yang berbeda.

\subsection{Modifikasi Untuk Memaksimalkan Throughput}

Kernel Bypass mengambil alih fungsi utama kernel pada bagian network menggunakan metode baru dengan mencoba teknik hashing pada signal yang bertujuan membagi quеие untuk diarahkan pada spesifik CPU seperti ditunjukkan dalam Gambar 4. Modifikasi ini bergantung pada kompabilitas dari ethernet card yang dipakai. Modifikasi ini dilakukan dengan perintah $r x$-flow-hash dikuti tupple pembaginya yaitu ip address dengan perintah $u d p 4$ dan tupple port dengan perintah $s d f n$.

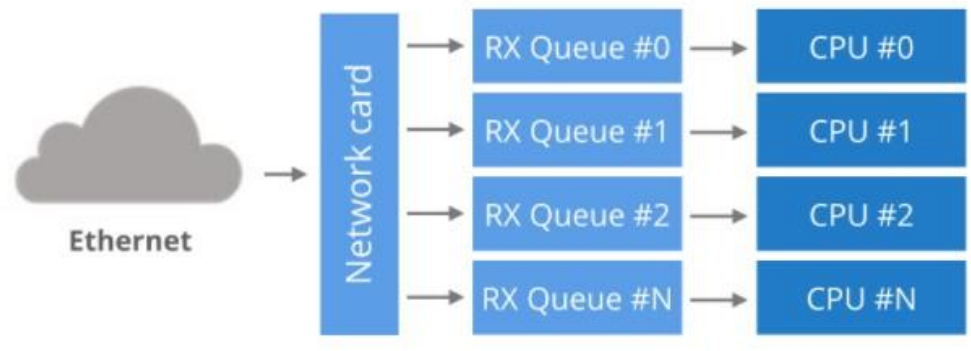

Gambar 4. Proses Hashing Signal 
Modifikasi berikutnya menggunakan multi IP (Internet Protocol) yang ditujukan untuk membagi beban CPU sehingga mengatasi limitasi CPU dalam mengolah atau memproses IRQ (Interupt Re Quest). Modifikasi ini umum untuk dilakukan dan bukan merupakan modifikasi yang baru. Dalam penelitian ini modifikasi dengan menambahkan ethernet card baru dengan IP yang berbeda dan sender diarahkan kedalam 2 IP tersebut.

Konsep multi threading sender diadopsi untuk melakukan modifikasi tahap selanjutnya yaitu multi threading receiver . Modifiksi ini dilakukan dengan taskset $-c$ 1,2 ./udpreceiver 1 0.0.0.0:4321 2 yang menunjukkan mengaktifkan CPU 1 dan 2 untuk menjalankan program udp receiver. Penerapan multi thread receiver merupakan penerapan dari penelitian (Rivera et al., 2014). Penerapan modifikasi ini memungkinkan terjadi penurunan throughput sehingga mengharuskan adanya modifikasi pada socket discriptor untuk menghindari lock pada multi core.

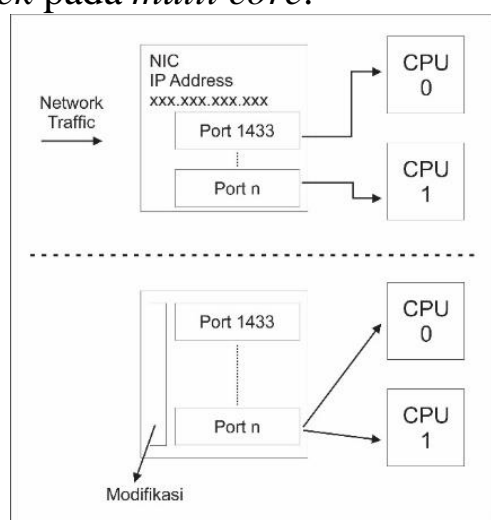

Gambar 5. Proses Modifikasi Port Listener

Penelitian ini menggunakan program untuk mengatasi perebutan lock dengan menggunakan multi listnener sehingga masing-masing thread menggunakan listenner yang berbeda sehingga meskipun menggunakan port yang sama dan tidak terjadi bottleneck. Modifikasi multi listenner ini dilakukan sebelum fungsi accept(). Penerimaan koneksi pada umumnya tidak melakukan fork atau binding socket sehingga semua core menggunakan mode waiting. Pada penelitian ini juga diterapkan affinity pada NIC IRQ sebagai pendamping sehingga meningkatkan performance proses seperti yang dilakukan oleh (Tsai et al., 2012).

\section{HASIL DAN PEMBAHASAN}

Percobaan ini dilakukan dengan 2 (dua) komputer yang dianggap sebagai sender atau client dan receiver atau dalam kenyataannya nanti disebut sebagai peladen. dengan melakukan standarisasi terlebih dahulu perangkat yang akan digunakan dengan melakukan raw prerouting dengan no track fitur pada port 4321 protokol UDP yang digunakan dalam keseluruhan percobaan. Penggunaan ip secara static juga dilakukan pada komputer sender dan komputer receiver sehingga menghilangkan hambatan konflik dengan iptables.

Kernel linux sudah menyediakan perintah send syscall namun untuk menghindari context switches namun memerlukan cost tersendiri sehingga dibentuk program baru dengan nama sender yang bertujuan mengirimkan generating packet ke peladen dengan protokol UDP dengan interval konstan seperti terlihat dalam Gambar 6 dan receiver dalam cuplikan Gambar 7. 


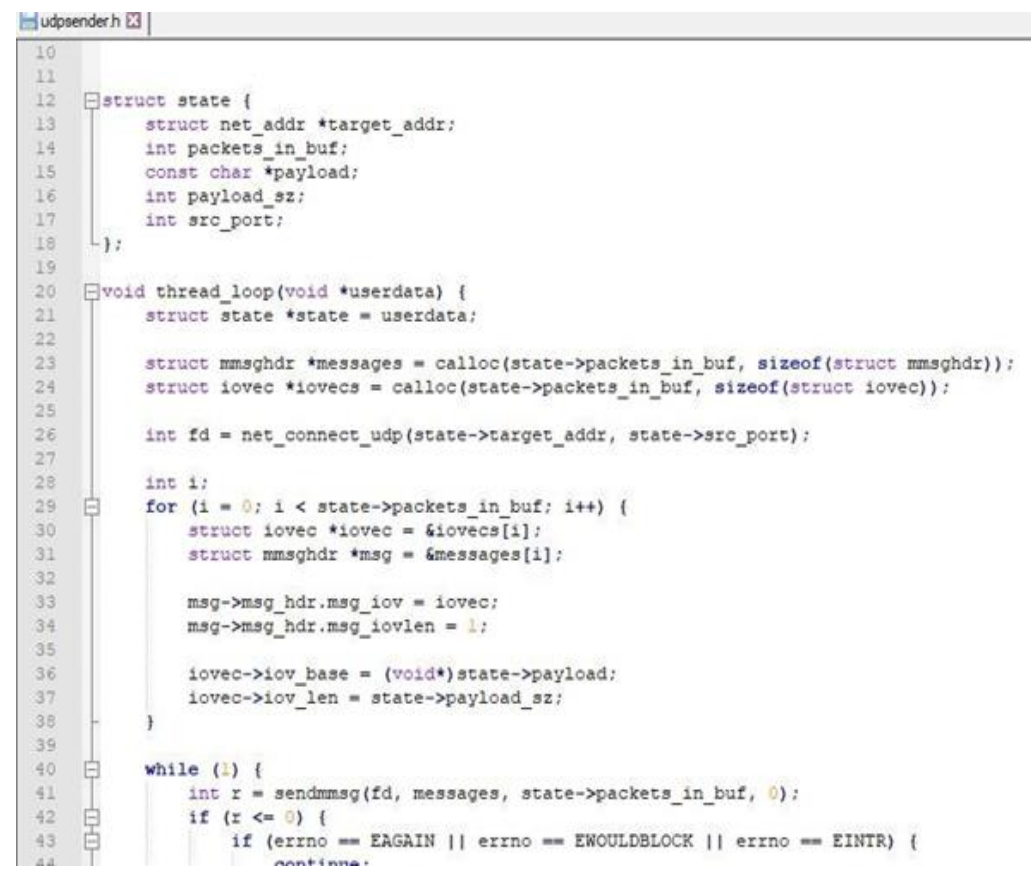

\section{Gambar 6. Cuplikan kode sender}

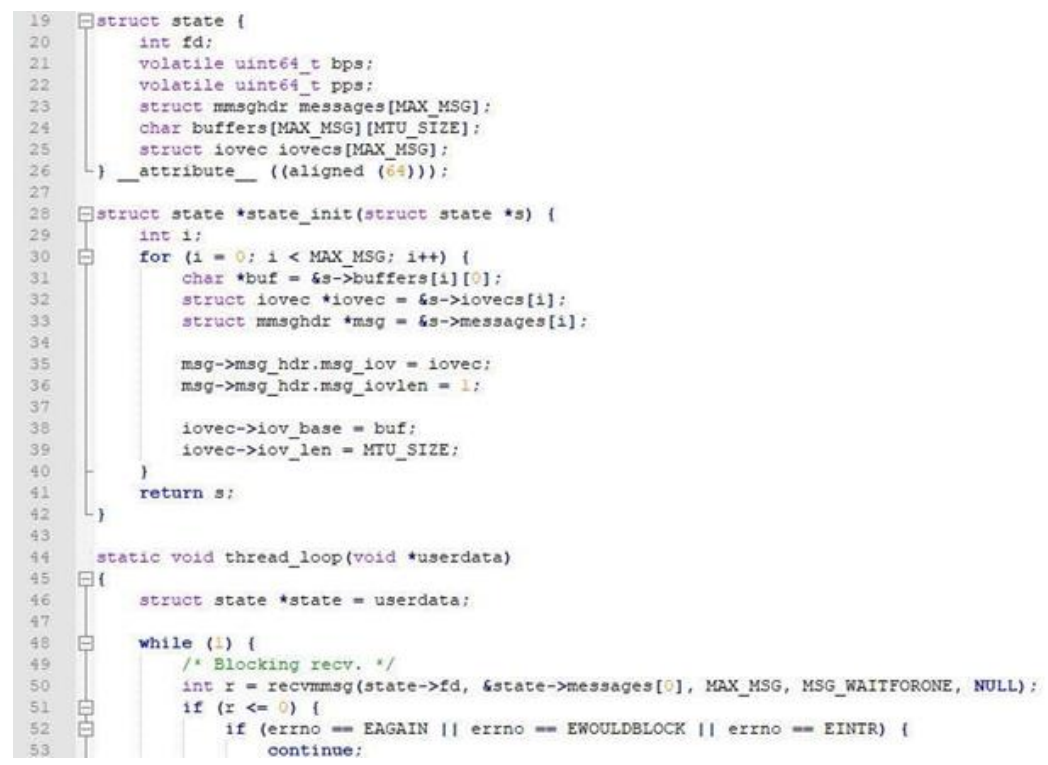

Gambar 7. Cuplikan kode receiver

Untuk mendapatkan default throughput di multicore server maka harus digunakan paramater perhitungan multithread yaitu menggunakan multithread sender seperti terlihat dalam gambar 8 dan penambahan pining CPU pada gambar 9.

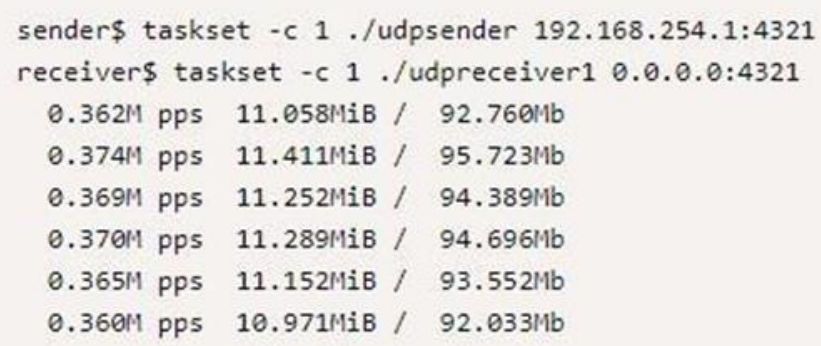

Gambar 8. Cuplikan perintah client server 


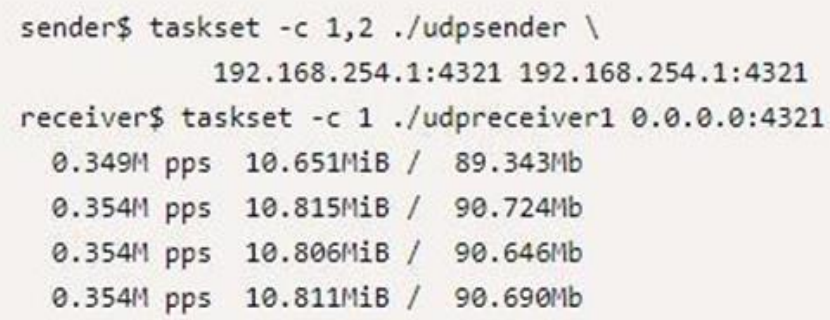

Gambar 9. Cuplikan perintah multitread dan pinning CPU

Gambar 8 dan 9 tidak terlihat perubahan namun dengan perintah ethtool -S akan memperlihatkan berapa paket maksimal dari sebuah multicore server default seperti terlihat dalam gambar 10. Dan angka pada gambar 8 dan 9 tidak menyentuh angka optimal disebabkan karena terdapat busy processor yaitu pada processor ke 6 seperti terlihat dalam gambar 11.

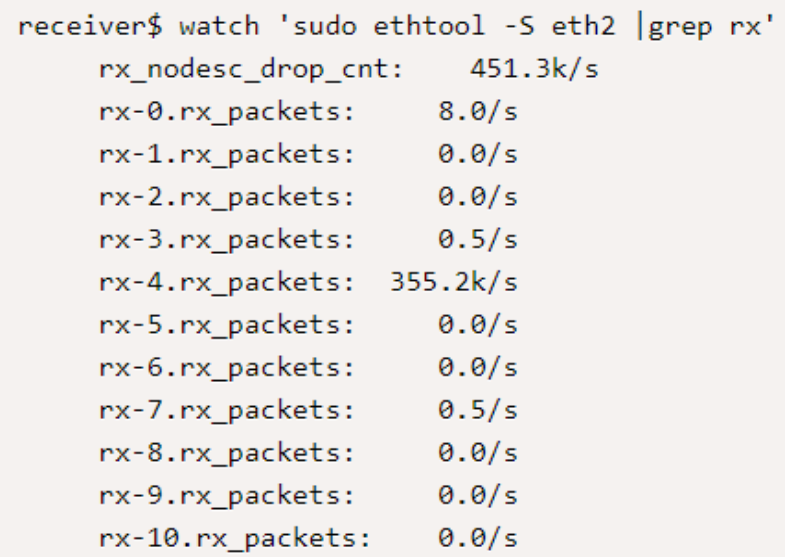

Gambar 10. Default througput multicore server

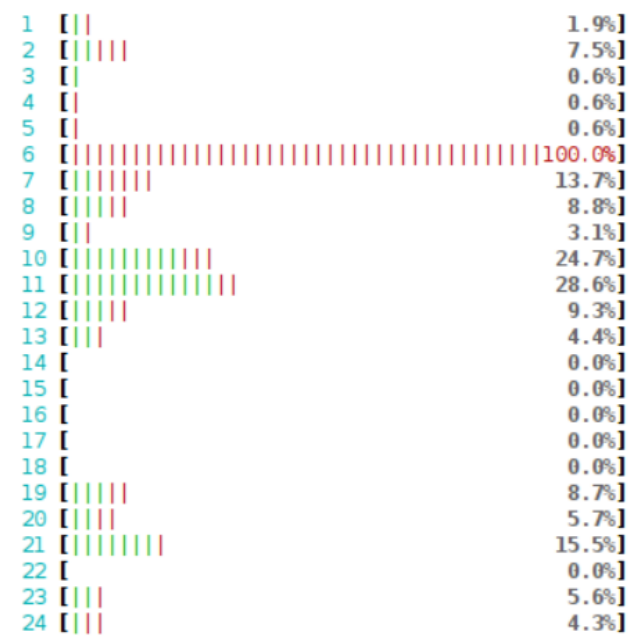

Gambar 11. Gambar htop busy processor

Percobaan menggunakan NUMA didapatkan beberapa hal sebagai berikut, receiver menggunakan CPU yang berbeda namun dengan node sama dengan rx queue didapatkan throughput diantara $360 \mathrm{kpps}$, receiver di CPU yang sama dengan node rx queue didapatkan sekitar 430kpps, receiver dalam shared core di teknologi HT akan mendapatkan sekitar 200kpps, receiver di numa node berbeda akan mendapatkan sekitar 330kpps. 
Modifikasi kernel bypass dimulai dengan mengoptimalkan receiver . Konsep tersebut mengambil persamaan dari multiple thread sender maka dimungkinkan juga multiple thread receiver namun terlebih dahulu dengan menambah ip address dengan menggunakan multi NIC card. Selanjutnya dieksekusi perintah dalam gambar 12 dan didapatkan hasil dalam gambar 13. Gambar 13 juga diperjelas dalam gambar 14 tentang sebaran paketnya menuju ke masing masing CPU.

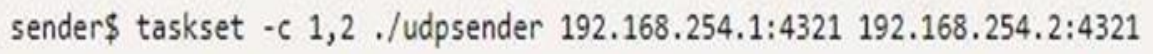

Gambar 12. Perintah multiple ip receiver

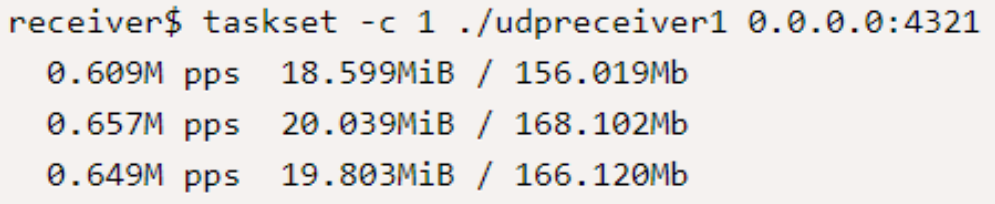

Gambar 13. throughput multiple ip receiver

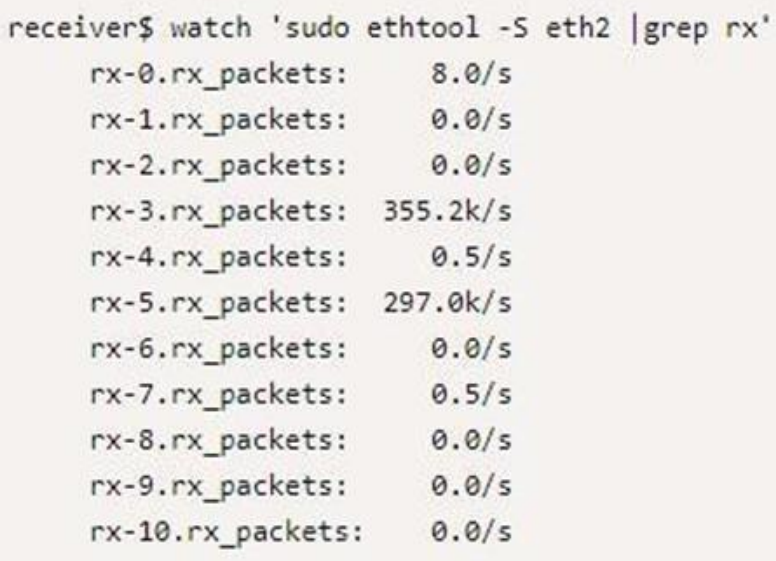

Gambar 14. Sebaran paket dalam multiple ip receiver

Modifikasi kernel bypass berlanjut dengan mengaplikasikan penerapan multiple thread receiver dengan melakukan affinity secara manual dengan perintah dan hasil terlihat dalam gambar 16. Gambar 16 juga menunjukkan penurunan yang dari sebelumnya berkisar di 650kpps menjadi berkisar 480pps. Modifikasi ini terlihat kurang memberikan peningkatan yang signifikan dan cenderung menurun dikarenakan adanya lock contection seperti ditunjukkan pada paper (Rivera et al., 2014). Perubahan berikutnya diletakkan pada port binding sehingga mampu mengatasi masalah lock contection. Port binding digunakan untuk meletakkan proses binding port sebelum fungsi accept () sehingga port yang sama dapat digunakan lebih dari sekali. Performance dari hasil modifikasi akan meningkat karena setiap port tidak dalam mode wait yang terlalu lama sehingga menurunkan utilisasi dari processor. Modifikasi tersebut dapat dilihat dari cuplikan kode mulport listener dalam Gambar 15. 


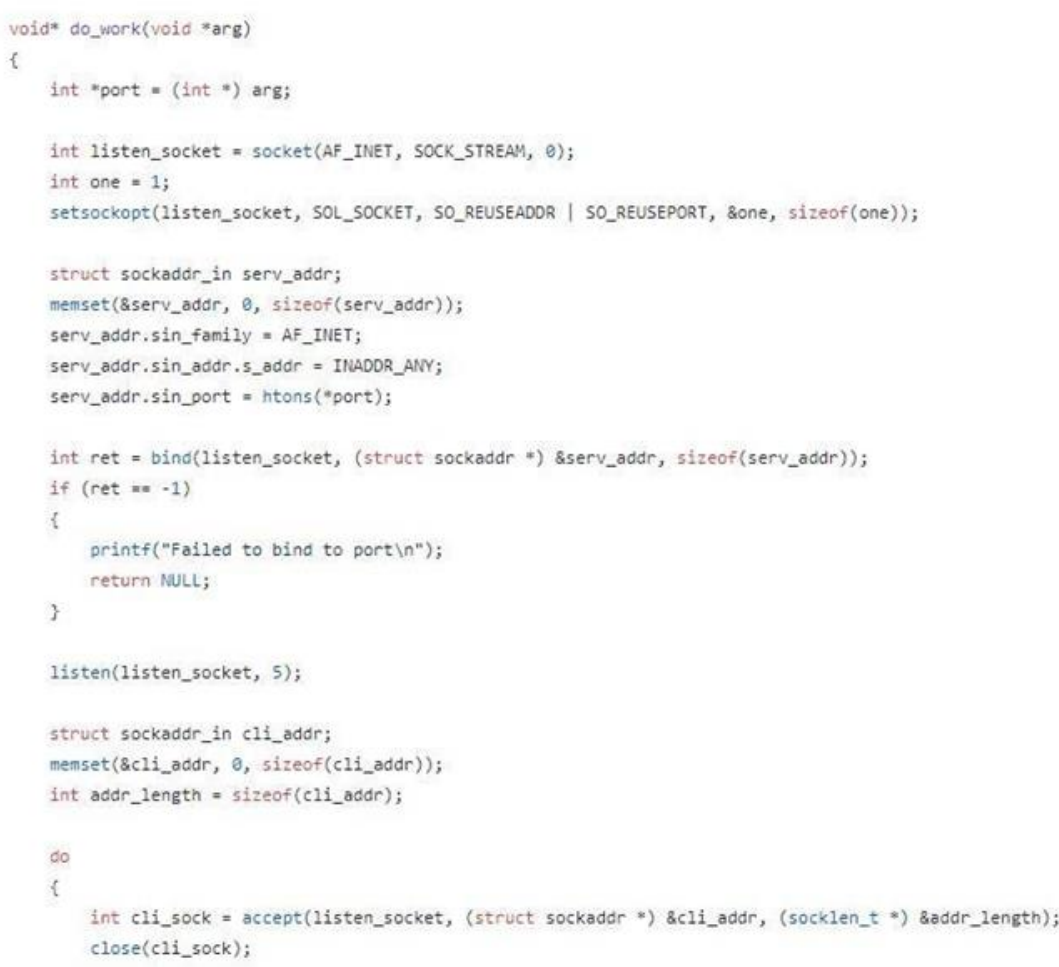

Gambar 15. Cuplikan code program multiport listener

Port binding membuat port yang sama dibuka oleh masing masing logical CPU sehingga dalam satu port terlihat dapat digunakan berkali kali dalam beberapa proses dari logical CPU yang berbeda. Cuplikan kode program dalam Gambar 15 dapat dikutip pada bagian listen yang melakukan binding sebanyak address yang dibutuhkan diikuti oleh socket yang tersedia di dalam hardware. Kode program tersebut merupakan bagian utama dari binding port yang memberikan perubahan yang cukup signifikan dalam mengatasi lock.

Modifikasi port binding membuat port listenner menjadi lebih banyak memberikan peningkatan signifikan dan merupakan kesuksesan dalam memberikan peningkatan througput seperti ditunjukkan dalam Gambar 16.

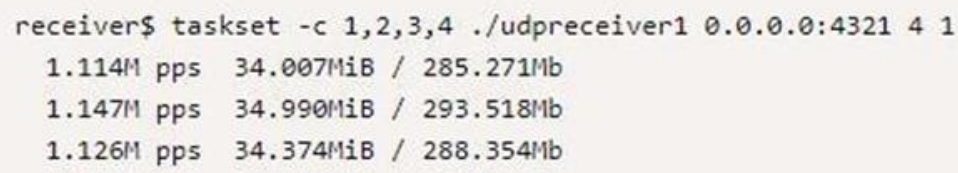

Gambar 15. Hasil modifikasi final kernel bypass

Tabel 1 menunjukkan hasil keseluruhan modifikasi yang dilakukan dalam menaikkan throughput sehingga mudah untuk diamati. Modifikasi dalam publikasi yang dilakukan mampu mengalahkan metode NUMA yang selama ini digunakan untuk menaikkan throughput. Penggunaan multiple thread receiver mengalami hambatan seperti yang dicontohkan oleh (Rivera et al., 2014) dipakai menjadi acuan untuk melakukan modifikasi dengan binding port sehingga memberikan hasil yang signifikan dalam prosesnya. Hasil modifikasi secara keseluruhan yang tertuang dalam tabel 1, jika dihitung dalam rata-rata akan menghasilkan kenaikan sebesar 250,44\%. 
Tabel 1. Hasil Modifikasi Througput

\begin{tabular}{|c|c|c|c|c|c|c|c|c|c|}
\hline \multirow[t]{2}{*}{ no } & \multirow[t]{2}{*}{ Default } & \multicolumn{2}{|c|}{ NUMA } & \multicolumn{2}{|c|}{ Multiple IP } & \multicolumn{2}{|c|}{ Multiple thread } & \multicolumn{2}{|c|}{ Binding port } \\
\hline & & $\begin{array}{c}\text { Throughput } \\
\text { (pps) }\end{array}$ & Gap (\%) & $\begin{array}{c}\text { Throughput } \\
\text { (pps) }\end{array}$ & Gap (\%) & $\begin{array}{c}\text { Througput } \\
\text { (pps) }\end{array}$ & Gap (\%) & $\begin{array}{c}\text { Throughput } \\
\text { (pps) }\end{array}$ & Gap (\%) \\
\hline 1 & $451,3 \mathrm{k}$ & $430 \mathrm{k}$ & 4,72 & $609 \mathrm{k}$ & 34,94 & $495 \mathrm{k}$ & 9,68 & $1114 \mathrm{k}$ & 246,84 \\
\hline 2 & & $428 \mathrm{k}$ & 5,16 & $657 \mathrm{k}$ & 45,58 & $480 \mathrm{k}$ & 6,36 & $1147 \mathrm{k}$ & 254,16 \\
\hline 3 & & $432 k$ & 4,28 & $649 \mathrm{k}$ & 43,81 & $461 \mathrm{k}$ & 2,15 & $1126 \mathrm{k}$ & 249,50 \\
\hline 4 & & $425 \mathrm{k}$ & 5,83 & $653 \mathrm{k}$ & 44,69 & $486 \mathrm{k}$ & 7,69 & $1138 \mathrm{k}$ & 252,16 \\
\hline 5 & & $427 \mathrm{k}$ & 5,38 & $640 \mathrm{k}$ & 41,81 & $490 \mathrm{k}$ & 8,58 & $1142 \mathrm{k}$ & 253,05 \\
\hline 6 & & $431 \mathrm{k}$ & 4,50 & $651 \mathrm{k}$ & 44,25 & $477 \mathrm{k}$ & 5,69 & $1129 \mathrm{k}$ & 250,16 \\
\hline 7 & & $428 \mathrm{k}$ & 5,16 & $655 \mathrm{k}$ & 45,14 & $485 \mathrm{k}$ & 7,47 & $1131 \mathrm{k}$ & 250,60 \\
\hline 8 & & $431 \mathrm{k}$ & 4,50 & $623 \mathrm{k}$ & 38,05 & $491 \mathrm{k}$ & 8,80 & $1136 \mathrm{k}$ & 251,72 \\
\hline 9 & & $433 \mathrm{k}$ & 4,05 & $641 \mathrm{k}$ & 42,03 & $481 \mathrm{k}$ & 6,58 & $1121 \mathrm{k}$ & 248,39 \\
\hline
\end{tabular}

\section{KESIMPULAN DAN SARAN}

\subsection{Kesimpulan}

Berdasarkan hasil penelitian dan pembahasan yang telah dilakukan, maka dapat disimpulkan beberapa hal sebagai berikut :

1. Sistem yang dikembangkan dengan menggunakan kernel bypass mampu untuk menaikkan kemampuan server ditunjukkan dengan kenaikan througput dibanding default kernel.

2. Dari hasil percobaan, kenaikan througput rata-rata adalah sebesar $250,44 \%$.

3. Hasil penelitian menunjukan HT (Hyper Threading) mampu meningkatkan kemampuan proses menjadi lebih cepat namun dalam penanganan program yang kompleks akan terjadi penurunan performance proses jika ditempatkan pada shared core.

\subsection{Saran}

Perlu adanya kombinasi yang lebih kompleks dan penelitian korelasi antar kombinasi serta urutannya sehingga dapat mewujudkan peladen yang lebih optimal dan menjadi standar secara umum.

\section{DAFTAR PUSTAKA}

Angelo, G. D., Marchetti-spaccamela, A., \& Cnr, I. (2016). Multiprocessor Real-Time Scheduling with Hierarchical Processor Affinities. 2016 28th Euromicro Conference on Real-Time Systems, 237-247. https://doi.org/10.1109/ECRTS.2016.24

Bo, Z. (2016). Analysis of the Resource Affinity in NUMA Architecture for High Performance Network. 2016 5th International Conference on Measurement, Instrumentation and Automation, 547-550.

Diener, M., Cruz, E. H. M., Alves, M. A. Z., Navaux, P. O. A., Busse, A., \& Heiss, H. U. (2016). Kernel-Based Thread and Data Mapping for Improved Memory Affinity. IEEE Transactions on Parallel and Distributed Systems, 27(9), 2653-2666. https://doi.org/10.1109/TPDS.2015.2504985

Fusco, F., \& Deri, L. (2010). High Speed Network Traffic Analysis with Commodity Multi-core Systems. proceedings of the 10th ACM SIGCOMM conference on Internet measurement, 218-224. 
Galagan, V., Yurchenko, O., Preobrazhensky, E., Zhuravkov, P., \& Dombrougov, M. (2013). Multi-gigabit intel-based software routers. Proceedings - RoEduNet IEEE International Conference. https://doi.org/10.1109/RoEduNet.2013.6714193

Gu, Q., Wen, L., Dai, F., Gong, H., Yang, Y., Xu, X., \& Feng, Z. (2014). StackPool: A high-performance scalable network architecture on multi-core servers. Proceedings 2013 IEEE International Conference on High Performance Computing and Communications, HPCC 2013 and 2013 IEEE International Conference on Embedded and Ubiquitous Computing, EUC 2013, 17-28. https://doi.org/10.1109/HPCC.and.EUC.2013.13

Hanford, N., Ahuja, V., Farrens, M., Ghosal, D., Balman, M., Pouyoul, E., \& Tierney, B. (2015). Improving network performance on multicore systems: Impact of core affinities on high throughput flows. Future Generation Computer Systems. https://doi.org/10.1016/j.future.2015.09.012

Huang, C., Yu, X., \& Luo, H. (2010). Research on high-speed network data stream capture based on multi-queue NIC and multi-core processor. ICIME 2010 - 2010 2nd IEEE International Conference on Information Management and Engineering, 2, 248-251. https://doi.org/10.1109/ICIME.2010.5477440

Jie, L., Shuhui, C., \& Jinshu, S. (2016). Implementation of TCP large receive offload on multi-core NPU platform. 2016 International Conference on Information and Communication Technology Convergence, ICTC 2016, 258-263. https://doi.org/10.1109/ICTC.2016.7763481

Rivera, D., Ach, E., \& Bustos-jim, J. (2014). Analysis of Linux UDP Sockets Concurrent Performance. 2014 33rd International Conference of the Chilean Computer Science Society, 65-69.

Shambharkar, S. A. (2015). A Study on Setting Processor or CPU Affinity in Multi-Core Architecture for Parallel Computing. International Journal of Science and Research, 4(5), 2013-2016.

Tsai, W. Y., Huang, N. F., \& Hung, H. W. (2012). A port-configuration assisted NIC IRQ affinitization scheme for multi-core packet forwarding applications. GLOBECOM IEEE Global Telecommunications Conference, 2547-2552. https://doi.org/10.1109/GLOCOM.2012.6503500 